\title{
Correction to: Effect of TELEmedicine for Inflammatory Bowel Disease on Patient Activation and Self-Efficacy
}

\author{
Zaid Bilgrami ${ }^{1} \cdot$ Ameer Abutaleb $^{1} \cdot$ Kenechukwu Chudy-Onwugaje ${ }^{1} \cdot$ Patricia Langenberg $^{1} \cdot$ Miguel Regueiro $^{2}$. \\ David A. Schwartz ${ }^{3}$. J. Kathleen Tracy ${ }^{1}$. Leyla Ghazi ${ }^{4}$. Seema A. Patil ${ }^{1}$. Sandra M. Quezada ${ }^{1}$. \\ Katharine M. Russman ${ }^{1}$. Charlene C. Quinn ${ }^{1}$. Guruprasad Jambaulikar ${ }^{5}$. Dawn B. Beaulieu ${ }^{3}$. Sara Horst ${ }^{3}$. \\ Raymond K. Cross Jr. ${ }^{1}$
}

Published online: 2 December 2019

(c) Springer Science+Business Media, LLC, part of Springer Nature 2019

\section{Correction to: Digestive Diseases and Sciences https://doi.org/10.1007/s10620-018-5433-5}

This manuscript is a secondary analysis of a large multicenter randomized controlled trial. The primary study is Cross RK et al., A Randomized Controlled Trial of TELEmedicine for patients with Inflammatory Bowel Disease (TELE-IBD). Am J Gastroenterol, 2019 Mar. https://doi. org/10.1038/s41395-018-0272-8.

Fig. 1 is adapted from a similar figure in the primary study referenced above.
In Table 1, the participant sample sizes are entered incorrectly. They should be $n=187$ total participants, $n=65$ in the standard care arm, $n=65$ in the TELE-IBD EoW arm, and $n=57$ in the TELE-IBD weekly arm.

Exclusion criteria can be found in the Study Participants section of the Methods.

Publisher's Note Springer Nature remains neutral with regard to jurisdictional claims in published maps and institutional affiliations.

The original article can be found online at https://doi.org/10.1007/ s10620-018-5433-5.

Raymond K. Cross Jr.

rcross@som.umaryland.edu

1 University of Maryland School of Medicine, 685 West Baltimore Street, Suite 8-00, Baltimore, MD 21201, USA

2 University of Pittsburgh School of Medicine, Pittsburgh, PA, USA

3 Vanderbilt University School of Medicine, Nashville, TN, USA

4 Dartmouth-Hitchcock Medical Center, Lebanon, NH, USA

5 Brigham and Women's Hospital, Boston, MA, USA 